\title{
DE INTERFACES TECNOLÓGICAS E RASCUNHOS DE EXPERIÊNCIAS
}

\author{
Rita Velloso* \\ ritavelloso@gmail.com
}

\begin{abstract}
RESUMO Discutem-se os efeitos de Internet sem fio, câmeras de vigilância, telas enormes de televisão em estações de metrô e tocadores de mp3 sobre a freqüientação dos espaços públicos, por meio da análise de alguns resultados do uso desses aparatos no cotidiano (e mesmo nas estratégias de planejamento) das cidades. Quando à experimentação do espaço arquitetônico (visível) faz-se somar uma rede (invisível) reconfiguradora de relações individuais e coletivas com os lugares, e o conceito de participação chega a uma condição limitrofe, exigindo perguntar até que ponto a materialidade da arquitetura é um componente necessário à transformação da experiência que está em curso.
\end{abstract}

Palavras-Chave Espaços Públicos; Participação; Experiência, Interfaces Digitais

ABSTRACT This paper discusses the effects of wireless internet, huge tv screens in subway stations, mp3players in public spaces occupancy. It analyses some results of these apparatus usage in everyday life of big cities, even in their planning strategies. It intends to put into question if that materiality concerning architecture is a necessary element to transformation of experience that is in course.

Keywords Public Spaces; Participation; Experience; Digital Interfaces

* Professora Titular da Universidade FUMEC/FEA, Professora Assistente da PUC Minas/Departamento de Arquitetura e Urbanismo. Artigo recebido em 15/09/05 e aprovado em 15/11/05.

KRITERION, Belo Horizonte, n 112, Dez/2005, p. 393-413 
para K. Imrad

Lá, não há um lá. Eles ensinavam isso às crianças ao explicar o ciberespaço. (William Gibson. Mona Lisa Overdrive.)

O jardim — a domesticação, a aculturação e a representação idealizada da natureza — agora está na máquina. (Hillis, K. Digital sensations.)

If clothes are the second skin of human beings, architecture is the third skin. (De Cauter. The capsular civilization: On the city in the age of fear)

1.

A arquitetura urbana atual não corroborou alguns prognósticos de teóricos da sociedade da informação. Na direção inversa daquela antevista em representações de futuro que afirmavam a superação da vida nas grandes cidades, a sociedade de informação permanece sociedade urbana. Contudo, transformações significativas já se operaram, se não exatamente na configuração material do espaço arquitetônico, pelo menos no que se refere a um, digamos, rearranjo de alguns elementos que estruturam conceitualmente este mesmo espaço arquitetônico e urbano. ${ }^{1}$

Refiro-me especificamente aqui aos resultados decorrentes do uso dos lugares quando mediado por aparatos tecnológicos. Já é possível mostrar que boa parte das tecnologias atuais de comunicação altera comportamentos e hábitos de freqüentação dos lugares, o que vem provocando alguns deslocamentos na experimentação corpórea da cidade. ${ }^{2}$

1 Por algum tempo, um número significativo de autores considerou que a tecnologia permitiria realizar a fantasia do lugar pós-urbano (anything/anywhere/anytime), ou ainda de uma certa utopia rural, uma vez que a característica definidora dessas tecnologias de comunicação e informação era justamente a capacidade de substituir as variadas formas de mobilidade física e a presença corpórea. Cf. GRAHAM. From dreams of transcendence to the remediation of urban life. In: GRAHAM (Ed.) Cybercities reader, p. 1-30. A tese da desurbanização foi discutida sobretudo nos Estados Unidos, onde o fenômeno dos subúrbios habitados pelas classes médias configura definitivamente a paisagem das grandes cidades desde a década de 1950. Mais recentemente, o urbanista Richard Plunz defende que a suburbanização é um pressuposto do consumismo atual, no qual o consumo é a um só tempo individualizado e de massa: "the consumer society and suburbanization go hand in hand." (traduzir) Cf. PATTEEUW. The conspiracy against the city, Lieven de Cauter in Conversation with Richard Plunz. In: PATTEEUW. Eine Stadt in Bewegung/Une Ville en Mouvement/ A Moving City, p. 20.

2 Neste texto assumo a hipótese de Henri Lefebvre de que o mundo contemporâneo configura uma sociedade completamente urbanizada: "a grande cidade explodiu, dando lugar a duvidosas excrecências: subúrbios, conjuntos residenciais ou complexos industriais, pequenos aglomerados satélites pouco diferentes de burgos urbanizados. As cidades pequenas e médias tornam-se dependências, semi-colônias das metrópoles". Lefebvre evoca a "prodigiosa extensão do 'urbano' a todo o planeta, isto é, a sociedade urbana, com suas virtualidades e seu horizonte." Cf. LEFEBVRE. A revolução urbana. Assim sendo adoto o termo arquitetura urbana para designar o conjunto dos lugares (edifícios, espaços públicos, espaços individuais espaços coletivos) de que trato aqui. 
Admitindo a tecnologia como força intermediadora presente na vida cotidiana, e que afeta a realidade experiencial corporificada, examino, a seguir, sua influência sobre a percepção contemporânea dos espaços e lugares que habitamos. Descreverei algumas situações de uso público dos espaços, discutindo os efeitos causados por uma crescente utilização de Internet sem fio, câmeras de vigilância onipresentes, telas de tv em alta resolução nas estações de metrô e pontos de ônibus, tocadores de mp3 e telefones celulares quase que invariavelmente acrescentados ao vestuário.

A análise dos fatos observados obedeceu a uma matriz conceitual, tanto fenomenológica quanto materialista, e à estratégia de descrever um material específico, no qual houvesse uma integração entre experiências pessoais e representações espaciais denotadoras da interação entre tecnologia e arquitetura. Em síntese, o objetivo deste texto é chegar a algumas observações teorizantes por meio de descrições dos modos segundo os quais as pessoas interagem corporalmente e combinam suas vidas cotidianas com a experimentação e o uso espacial dos media eletrônicos e das tecnologias da comunicação.

Em primeiro lugar, mostrarei que, uma vez dada essa condição de mediação tecnológica, o conceito de participação dos habitantes na arquitetura chega a uma posição limítrofe, o que, em boa medida, passa a exigir uma redefinição de tal conceito, se quisermos assumir sua validade de modo radical. Em segundo e último lugar, discutirei até que ponto a materialidade da arquitetura é uma variável componente da transformação da experiência que está evidentemente em curso na cultura urbana de nossos dias, quando, à experimentação do espaço arquitetônico (visível), faz-se somar uma rede (invisível) reconfiguradora de relações individuais e coletivas com os lugares.

\section{2.}

Walter Benjamin afirmava que, ao viver em uma grande cidade, compreendemos o mundo por meio de uma apropriação tátil das coisas, somada ao olhar distraído que dirigimos a estas. Assim se caracteriza a singularidade da percepção espacial em uma metrópole: uma experiência corpórea que oscila continuadamente entre "misturar-se" com as coisas ou vê-las de relance, mas, em qualquer dos casos, atitude marcadamente empírica, cujo resultado, tal como disse Benjamin, "revela aspectos fisiognômicos que residem nas coisas minúsculas". Entretanto, esta não é uma experiência solipsista, pois refere-se, antes, à comunicabilidade envolvida na lida concreta com o mundo.

Para usar a terminologia de uma e outra correntes filosóficas aqui subjacentes, pode ser dito que cada situação espaço-temporal em que se 
desenrola a experiência humana se configura em uma materialidade demarcada tanto subjetiva quanto intersubjetivamente. ${ }^{3}$ Diz respeito a um engajamento corpóreo não apenas em relação às coisas (objetos), mas também a outros sujeitos e à circunvizinhança (entorno) de quem faz a experiência. Tais conceitos (engajamento corpóreo, intersubjetividade, distração, apropriação tátil, comunicabilidade) ajustam-se bem à experiência que aqui está em questão aquela que resulta do uso de variados equipamentos tecnológicos no ambiente urbano; na realidade, um jogo entre o corpo e o espaço, em uma relação mediada em diversos graus pela tecnologia.

Não é preciso sequer sair de casa para entender com quais variáveis lidamos ao tratar desse assunto. Muito provavelmente a maioria de nós já aderiu entusiasticamente à conexão Skype ou já precisou regular o tempo dispendido por algum adolescente ou por si próprio em frente às telas do messenger. Isso tampouco é um fenômeno recentíssimo: enquanto em 1992 poucos de nós dávamos notícia do que fosse a Internet, uma década depois os números do acesso à Associated Press no site do America On Line, em onze de setembro, são impressionantes: naquele único dia houve um milhão de visitas e, nos dias que se seguiram, pelo site da AOL passaram um bilhão e duzentos milhões de mensagens instantâneas. ${ }^{4}$ Atualmente, de tempos em tempos, os cadernos dominicais dos jornais e as revistas semanais discutem as alterações no que chamam "geografia espacial da casa", em geral alertando os pais a "colocarem o computador da casa em uma área comum a todos os familiares", para facilitar o controle dos acessos.

Ou seja, ainda que não nos tenhamos dado conta, tomamos parte neste jogo: alguns mais, outros menos e uns poucos distantes - e à lógica que sustenta tal jogo nem a ausência é algo estranho, pois, a concordar com os teóricos das primeiras metrópoles do século XIX, viver em um ambiente urbano sempre foi jogar pela regra da inovação técnica, estando conscientes ou não, em um amálgama de experiência e medo imaginário e em uma oscilação entre pertencer e querer desgarrar-se, pois ficar próximo ou afastar-se sempre foi a baliza da vida moderna, e recusar-se à estimulação é parte do leque de atitudes que configura o comportamento dos indivíduos urbanos. Georg Simmel já

3 Como escreveu Carl Schorske sobre as correlações entre história urbana e filosofia européia,"ninguém pensa a cidade num isolamento hermético. Forma-se uma imagem dela por meio de um filtro da percepção derivado da cultura herdada e transformado pela experiência pessoal". SCHORSKE. A idéia de cidade no pensamento europeu: de Voltaire a Spengler. In: Pensando com a História. Indagações na passagem para o Modernismo, p. 53-72.

4 GRAHAM. Excavating the material geographies of cybercities, p. 144: o ataque ao World Trade Center é o site mais buscado ainda hoje, atrás apenas de Nostradamus, que é o primeiro lugar, e outros cinco sites de pornografia. 
assinalava que distância e aversão são o complemento exato de reação e envolvimento, e juntos configuram o conjunto de possibilidades de acomodação dos sentidos aos conteúdos e às formas da vida metropolitana. ${ }^{5}$ Quando Simmel escreveu a respeito dos efeitos da metrópole sobre a vida mental (Nervenleben), o fez chamando a cidade de arena de luta e reconciliação entre dois modos de vida que, a partir do século XIX, viriam redefinir o papel do indivíduo na cultura moderna. A presença da tecnologia nas grandes cidades compôs indubitavelmente as formas de vida urbana, a tal ponto que esta, se, por um lado, "é mais e mais composta de conteúdos impessoais e ofertas que tendem a deslocar as colorações e peculiaridades genuinamente pessoais ${ }^{6 "}$; por outro, na contrapartida do jogo, é vida que pode se tornar "infinitamente fácil para a personalidade à qual tantos estímulos, oportunidades, interesses, usos do tempo e usos da consciência são oferecidos de todos os lados. Tudo isso carrega uma pessoa como se fosse um rio, e ninguém precisa se esforçar em nadar. ${ }^{\text {" }}$

A cidade que hoje é assim não o seria sem a tecnologia. A cada vez que é preciso destrinchar as complexas relações entre tecnologia e grandes cidades, a afirmativa de Benjamin sobre a transformação da percepção tem enorme ressonância: não mudaram apenas os aspectos materiais da vida humana ao longo do tempo; antes, é a percepção humana que se reorganiza continuadamente. Tal reorganização interna configuraria os diversos modos históricos segundo os quais as pessoas lidam com objetos do mundo externo, sendo, a um só tempo, condição e resultado destes. ${ }^{8}$ Se considerarmos como fator crucial na história das cidades capitais ou das regiões metropolitanas do século XX o crescimento exponencial de produção, distribuição e consumo de aparatos tecnológicos — que vão da eletricidade à tecnologia eletrônica —, a

5 Ver a este respeito as atitudes de reserva e indiferença de que falou Georg Simmel em A metrópole e a vida mental: "this outer reserve is not only indifference but, more often than we are aware, it is a slight aversion, a mutual strangeness and repulsion, which will break into hatred and fight at the moment of a closer contact, however caused. The whole inner organization of such an extensive communicative life rests upon an extremely varied hierarchy is not as large as might appear on the surface. Our psychic activity still responds to almost every impression of somebody else with a somewhat distinct feeling." Cf. SIMMEL. The Metropolis and the mental life. In: FEATHERSTONE; FRISBY. Simmel on Culture, p. 174-190. Cf. também sobre isso a idéia de agoraphobia nos textos de Anthony Vidler, especialmente em The warped Space.

6 SIMMEL. The Metropolis and the mental life. In: FEATHERSTONE; FRISBY. Simmel on Culture, p. 174190.

7 SIMMEL. The Metropolis and the mental life. In: FEATHERSTONE; FRISBY. Simmel on Culture, p. 174190.

8 "Just as the entire mode of existence of human collective changes over long historical periods, so too does their mode of perception. The way in which human perception is organized - the medium in which it occurs - is conditioned not only by nature but by history. Reception in distraction - the sort of reception which is increasingly noticeable in all areas of art is a symptom of profound changes in apperception." BENJAMIN. The work of Art in the age of its technological reproducibility. In: BENJAMIN. Selected Writings, p. 101-133. 
compreensão da dinâmica urbana novecentista permite inferir que as cidades crescem e se consolidam especialmente em decorrência da oferta de tecnologias da comunicação, ${ }^{9}$ daí se seguindo que uma análise das estruturas atuais da percepção humana deverá incluir necessariamente a dimensão comunicativa da vida urbana. É especificamente na interseção entre as táticas individuais e coletivas dos moradores e o uso de tecnologia de comunicação que se pode verificar quão profundamente se alterou a cultura material novecentista, passando a refletir nossas percepções modificadas sobretudo em relação ao espaço e aos aparatos que a ele estão atados.

Na década de 1960, a arquitetura apontou de modo bastante enfático, esta inervação das cidades pelo par comunicação/informação, tornando-o tema de muitos experimentos projetuais. $\mathrm{O}$ fato de que as propostas mais radicais nessa direção tenham ficado à margem de certo padrão de desenvolvimento dos ambientes construídos diz muito sobre uma incapacidade (ou ingenuidade) da arquitetura àquela altura do século XX, para lidar com a tecnologia da comunicação enquanto fator de alteração da experiência espacial. ${ }^{10}$ Sobraram metáforas e alegorias, enquanto a vida ordinária das pessoas nas cidades avançava exatamente à revelia ou apesar do conservadorismo arquitetônico e urbano, e o cotidiano ia se modificando em função de eletrodomésticos, dispositivos eletrônicos e outros tantos gadgets campeões de audiência do consumo mais popular.

Nas condições atuais, autores de teoria da arquitetura aferem a interação comunicativa entre objetos usados/lugares freqüentados por pessoas, adotando posições diversas. É relevante a abordagem de Dalibor Vesely, que, seguindo

9 Tom Standage, editor de tecnologia da revista The Economist, escreveu uma espécie de "pré-história" da Internet a partir da tese de que telégrafo e Internet constituem uma linha de descendência. "The Victorian Internet, was published in 1998 in Britain and North America. It points out the features common to the telegraph networks of the nineteenth century and the internet of today: hype, scepticism, hackers, on-line romances and weddings, chat-rooms, flame wars, information overload, predictions of imminent world peace, and so on. In the process, I get to make fun of the internet, by showing that even such a quintessentially modern technology actually has roots going back a long way (in this case, to a bunch of electrified monks in 1746)". Cf. o texto integral do livro em http://tomstandage.com/vicnet.html. A introdução do telégrafo marca uma importante ruptura, a partir do (momento?) que, por causa da velocidade do telégrafo, as pessoas passaram a igualar a comunicação à transmissão de mensagens pelo espaço.

10 SADLER. Non plan, p. 149: "communication, long a central concern on modernism, becomes an ecstatic condition in experimental work of the 1960s, the breakdown of the 'architectural interface' tantalizing close in cybernetics, experiments with computer-aided design, and the welter of communications theory. If Marshall McLuhan could bring an insight into media, and Timothy Leary the hallucinogens, then the architectural avant-garde reckoned it might have the environmental techniques (...). Utopian propositions into a built reality of festive interchange between people, performers and architecture. (...) Here was a anew architectural ethos, a search for an architecture of intimacy that would pare away the barriers between one's mind, body, other bodies and the environment." 
os passos de Gadamer quanto à imbricação de interpretação e situação dialógica, ${ }^{11}$ e, em muitos momentos, ecoando também o conceito de experiência de Walter Benjamin, discute longamente a natureza do vínculo entre arquitetura e comunicação. ${ }^{12}$ No caso desta teoria, não mais se trata de focar neste ou naquele atributo formal ou imagético de um edifício ou lugar urbano, mas, antes, de pautar os efeitos do espaço habitado sobre o usuário, este último entendido como protagonista em uma ação progressiva de seleção e definição das necessidades de um lugar arquitetônico.

Dalibor Vesely parte da premissa de que a constituição de um espaço coerente é permitida pela capacidade do corpo humano de situar-se por meio de níveis sucessivos de experiência (movimentos corporais, envolvimento corpóreo, experiência perceptiva, imagens conceituais e pensamentos), configurando o que ele denomina "horizonte de todas as nossas experiências" ou espacialidade. ${ }^{13}$

O movimento do corpo — nível primeiro da experiência — entre elementos do espaço arquitetural cria um espaço comunicativo, na medida em que, ao nos movimentarmos, aprendemos e adquirimos a habilidade de freqüentar um lugar. O movimento ativa as relações geométricas entre coisas e espaço e, por isso, é condição suficiente para nossa percepção de propriedades ambientais. Graças à compreensão das partes constitutivas de um objeto arquitetônico, alcançada por meio do movimento do corpo que explora o espaço físico, conforma-se para o habitante uma situação que cumpre o papel sintético de estruturar a experiência subjetiva, na qual a motilidade é responsável por conferir à arquitetura não apenas o status de medium, mas também de componente estruturante de identidades e permanências. ${ }^{14}$ Neste raciocínio, a

11 Dalibor Vesely (DipEng DipArch MA PhD) nasceu em Praga, onde estudou Arquitetura e História de Arte. Hoje é professor titular na Escola de Arquitetura na Universidade de Cambridge; ele leciona uma unidade do studio de graduação, orientada para a arquitetura de cidades. Co-dirige o curso de M. Phil em História e Filosofia de Arquitetura. Seus interesses incluem poética e hermenêutica de arquitetura, e suas pesquisas e publicações refletem uma tentativa sistemática de restabelecer a compreensão humanística da arquitetura. É bastante nítida a influência da obra de Gadamer nos textos de Vesely, sobretudo pelas referências a Verdade e Método, especificamente ao capítulo que se intitula "Experiência hermenêutica".

12 VESELY. The Nature of communicative space. In: VESELY. Architecture in the age of divided representation. The question of creativity in the shadow of production, p. 43-108.

13 VESELY. Architecture in the age of divided representation. The question of creativity in the shadow of production, p. 49: "the primordial form of spatiality is a horizon of all our experiences, but it is a horizon which cannot be in principle ever reached and thematized in our express perception. (...) Space is only a dimension (...). It would be more appropriate to speak about the spatiatiality of the world so that the structure, topography and orientation of space could receive their proper ontological meaning".

14 "Identity not as a property of things or structures; it is constituted in the continuity of references to the ultimate sameness of the most regular movement in reality as a whole." Cf. VESELY. Architecture in the age of divided representation. The question of creativity in the shadow of production, p. 48-59; Cf. também p. 79 e 369 . 
arquitetura somente se efetivaria, ou se tornaria real, na performance, isto é, quando uma ação fosse desempenhada no lugar. ${ }^{15}$

Tem-se aqui uma definição de arquitetura a partir do seu efeito, cunhada na interseção entre o individual e o particular, isto é, arquitetura como espaço habitado, como situação da vida cotidiana em que os gestos traduzem o aprendizado de um comportamento e a familiaridade espacial que se adquiriu. ${ }^{16}$

Trata-se de uma descrição fenomenológica do espaço em ato, pois não é apenas uma enumeração de elementos constituintes do espaço, mas também uma estratificação do fenômeno espaço, configurado necessariamente em uma dimensão temporal e segundo a ação de um sujeito. São os gestos e os percursos de um indivíduo que delineiam (e, em boa medida, definem) a experiência humana do espaço. Nesta acepção do vivido, o conceito estabelece-se para além do espaço geométrico (espaço mental concebido pela matemática) e espaço físico (na dimensão prático-sensível, de percepção da natureza). O ambiente construído, além de ser um instrumento de mediação, é também de tradução, pelo que cada edifício intrinsecamente exigiria do habitante uma experimentação versátil, na mesma medida em que a ele se apresentaria de muitos modos. ${ }^{17}$ Graças a seu conteúdo comunicacional a arquitetura pode ser considerada como invariavelmente experiencial; pode-se ir mais além e dizer, com Vesely, que o uso - enquanto experiência do lugar — é a vida concreta de um objeto concebido por um arquiteto.

Vejamos como esta posição teórica se comporta em relação ao tópico em discussão aqui, qual seja, se a experiência da cidade é primeiramente corpórea, ela é, hoje, mediada pelas tecnologias de comunicação e informação; em outros termos, assume-se que a tecnologia da comunicação afeta decisivamente os modos pelos quais experienciamos o mundo urbano, por mais plurais e flexionados que sejam seus arranjos de lugar e ambiente construído.

15 Vesely chama a isso "the spatial setting of a situation". Cf. VESELY. Architecture in the age of divided representation. The question of creativity in the shadow of production, p. 75. Cf. também DEWSBURY. Performativity and the event. Performar denota sempre uma ação, "no sentido da experimentação que nos é exigida todos os dias". O termo performance vem do verbo inglês to perform "alcançar", "executar" e, este, do fr. ant. parfourmer "cumprir, acabar, concluir", de former "formar, dar forma a, criar", do lat. formare "formar, dar forma".

16 "In everyday life gestures represent an important step in the mimetic formation of typical situations and in the formation of space." Cf. VESELY. Architecture in the age of divided representation. The question of creativity in the shadow of production, p. 71.

17 VESELY. Architecture in the age of divided representation, p. 106: "It is only by resistance that architecture supports our intentions and the appropriate meaning of a particular situation. We are aware of this mostly intuitively each time we move up a staircase, travel through uncomfortable corridors, enter rooms with certain expectations, or recognize the purpose of a building from its layout and physiognomy". 


\section{3.}

Admitindo que as tecnologias de comunicação e informação contribuem para reconfigurar a percepção do espaço (os fluxos) e do tempo (os ritmos), meus exemplos de predileção serão aqui, até um tanto obviamente, os telefones móveis e o iPod (ou seus correlatos: walkman, discman ou quaisquer equivalentes tocadores de mp3). Todos são, em suma, utensílios digitais móveis e personalizados, funcionando como interfaces-chave por meio das quais muitos moradores urbanos delineiam, configuram e praticam suas atividades urbanas. Cada um, telefone celular e toca-mp3, conforma uma peculiar experiência individual de construção de uma atmosfera, em certa medida, suspensiva da cidade.

Enquanto interfaces, funcionam como uma espécie de membrana, recobrindo o humano, e são zonas fronteiriças sensíveis de negociação entre o indivíduo, seu entorno e o universo maquínico. ${ }^{18}$ É notável observar uma calçada no centro da cidade, repleta de gente, cada qual munida com seus minúsculos fones de ouvido, movendo-se no interior de uma bolha virtual. $\mathrm{O}$ iPod materializa o isolamento consentido, mantendo a distância as outras pessoas, os sons indistintos da cidade, o ruído das ruas e explicitando algo que, desde sempre sabíamos, mas que, agora, assume-se socialmente de maneira silenciosa, por todo o conjunto de pessoas à sua volta. Cada ser humano, se já compreendia o mundo a partir de seus filtros particulares, agora evidencia o procedimento dessa compreensão, que não é outro senão o de apartar-se da possibilidade de comunicar a experiência, e sem que isso sequer cause alguma estranheza nos transeuntes urbanos. ${ }^{19}$ Mas o que chama a atenção é que essa maneira individual de experimentar o mundo esteja exacerbada no hábito de portar um aparato que explicite ao outro o quanto você se separa dele.

Não obstante ficarem suspensas as condições do diálogo (e, portanto, da troca comunicativa), na mesma medida em que a cidade, este procedimento desvela os esboços de uma nova interação social. Se um aparato de tecnologia de comunicação e informação começa a influenciar processos e experiências na vida urbana, considerar algo como um espaço dialógico entre habitantes das grandes cidades a ser estabelecido no fluxo diário das atividades implica incluir na conta da intersubjetividade o ponto cego e inaudível que demarca o quanto cada um vive dentro da própria "trilha sonora da minha vida". E, dessa

18 SANTAELLA. Culturas e artes do pós-humano: da cultura das mídias à cibercultura.

19 Foram seis milhões de iPods vendidos até o segundo trimestre de 2005. A despeito de uma grande variedade de fabricantes, a Apple detém atualmente $70 \%$ do mercado de reprodutores de música digital e cerca de $80 \%$ do segmento de vendas de músicas on-line, pela loja virtual iTunes. 
vez, essa trilha não se desenhou com as músicas que, por acaso, tenham embalado seus encontros, as saídas para dançar, um rádio tocando alto na rua, o disco no restaurante, pois, neste caso, a música tem a função de matizar a experiência individual do espaço, sobrepondo-se à visualidade obrigatória deste, freqüentemente desmaterializando-o.

O telefone celular, por sua vez, é atualmente a mais bem acabada ilustração da mobilidade e da recombinação do uso das ruas por meio de tecnologias de comunicação e informação. Seu uso faz com que o transeunte se destaque do real circundante, na direção de um universo particular em meio à cena urbana, $o$ que, de certo modo, reconfigura os âmbitos privado e público, pois que implica em uma forma de privatização do espaço público. O telefone móvel mudou o ato de caminhar, com as ruas tornando-se verdadeiras e literais vias de informação, reunindo trocas eletrônicas, espaços e transportes públicos. Considerada a espacialidade, pode-se afirmar que ele permite criar um terceiro lugar, que é uma espécie de paisagem para o encontro particular em meio à cena urbana. De uma perspectiva temporal, ao falar em um telefone enquanto se movimentam, os habitantes urbanos vivem a ilusão de um presente contínuo, simulam o paralelismo de duas vidas: a que se desenrola enquanto freqüentam um determinado espaço; e uma outra, a que controlam ou a partir de onde são controlados, e à qual se reportam via ligação telefônica. Repare-se, a este respeito, que, muitas vezes, as descrições espaciais são parte do diálogo. As conversas incluem a menção sobre onde estão e o que fazem quem liga e quem recebe a chamada — as respectivas paisagens passando a ser ocasionalmente o terceiro na conversa. ${ }^{20}$ Tudo isso para não mencionar a derivação supérflua no consumo, cujo âmbito produtivo certamente comemora um objeto que, nascido da mais perfeita conjunção funcional de economia e tempo, e gerado para operar no mais ajustado âmbito de produtividade e controle que demarca o mundo administrado, tenha acabado por encontrar na falta de utilidade seu uso mais corrente: basta observar este ícone da eficiência invariavelmente presente nas mãos dos adolescentes - quando então se revela um brinquedo que potencializa o hábito de jogar conversa fora em intermináveis diálogos sobre tudo e nada.

No que concerne ao movimento, ou ao espaço comunicativo que um habitante estabelece no seu entorno urbano, ambos, celular e iPod, são máquinas que dão nova forma à interação do corpo com o ambiente, confirmando o que Benjamin falava já nos anos 1930. Para freqüentar a cidade não é mais necessário estar atento a ela, uma vez que é mesmo distraidamente que se constitui a experiência

20 Os telefones móveis são freqüentemente usados para expressar o movimento e sua direção recombinando trocas eletrônicas, espaços e transportes públicos: "Mãe, estou no ponto de ônibus", "estou entrando no táxi", "estou descendo a escada rolante", "estou dentro do trem" etc. 
cotidiana urbana. Entretanto, o que é de se notar, neste caso, é que, à já usual fragmentação visual feita da coleção de imagens que alguém recorta enquanto caminha ou trafega pela cidade, vem somar-se a solicitação de outros sentidos humanos; e o aparato tecnológico, se, por um lado, isola e protege, por outro, inscreve o corpo de uma nova maneira no ambiente.

Refiro-me a uma preocupação das ruas baseada em sutis mudanças no deslocamento e na permanência, que confere nova feição à apropriação do território por um usuário. Quando definida a partir de um conceito de experiência da arquitetura, a apropriação de um lugar por parte de seu habitante caracteriza-se como aquilo que decorre da conjunção que se estabelece entre o espaço dado e os aparatos que tornam possível o desempenho das atividades. Dado um determinado lugar, a condição necessária para gerar apropriação é o desenrolar das atividades dentro dele. Conseqüentemente, a distribuição espacial não é mais tão crucial quanto a interação comunicativa que objetos e espaço permitem. Porém, no tocante à vida urbana, é preciso perguntar pela natureza das ações desse usuário que porta um iPod e fala a um telefone móvel; indagar em que medida ele conseguiria protagonizar aquela ação "de seleção e definição de necessidades" de que fala Vesely.

\section{4.}

Nesta oscilação entre ouvir sozinho suas próprias músicas e reportar-se pela fala a outro lugar, estabelece-se um jogo entre envolvência/recusa, no qual a cidade experimentada se condensa e se satura. Se é incontestável que, nestas condições, quanto ao comportamento das pessoas em relação à sua própria espacialidade (definida pelo movimento), a vida cotidiana fica revigorada, não é suficientemente nítido se daí decorre qualquer transformação na produção do ambiente urbano. Devemos perguntar, afinal, até que ponto a materialidade da arquitetura é um componente necessário à transformação da experiência que está em curso.

Já terá a arquitetura, de algum modo, acatado dentre suas premissas de desenho este novo engajamento das pessoas com seus lugares - pois, sim, elas vêm estabelecendo um novo modo para lidar com a materialidade do seu ambiente? Em cada descrição de freqüentação dos espaços causada pelos aparatos tecnológicos nota-se que o uso pode ser criativo apesar da arquitetura (no extremo, diz-se que "a forma pode ser qualquer uma, uma vez que eu sou de qualquer modo indiferente a ela"), ou seja, é perfeitamente plausível que formas arquitetônicas conservadoras em um contexto urbano estabelecido acolham práticas com alguma dose de autonomia, se não exatamente criativas, 
práticas que se fazem ajustar para permitir a sobrevivência. Entendo que aqui esteja uma tarefa para a arquitetura, pois diz respeito ao engajamento do habitante na produção do seu ambiente. E é aqui onde o conceito de participação chega a uma posição limítrofe, exigindo ser reconsiderado.

Para entender como a produção dos espaços lida com estas formas de engajamento e participação em mutação, é preciso analisar situações em que o avanço nas aplicações dos meios de tecnologia de comunicação e informação não esconde sua opacidade, que diz respeito à apatia ou indiferença - e à alienação a elas intrínseca - com a qual se comportam habitantes urbanos, de que o melhor exemplo parece ser a infeliz decisão de colocar TVs gigantes, com áudio de cinema, em algumas das mais movimentadas estações de metrô mundo afora. As enormes telas - painéis que informam a temperatura externa, o tempo entre o próximo trem e o seguinte e o noticiário que retransmite a programação de um canal de notícias 24 horas — são um paliativo na breve espera dos trens, colhendo os transeuntes em ânimos absortos e gestos hipnotizados. Ao mesmo tempo, câmeras e espelhos convexos espalham-se pelos túneis de acesso ao metrô, registrando a distância os comportamentos, mas a população parece não mais se incomodar com a vigilância permanente, uma vez que, seja em um país na América Latina, seja na Ásia, assentam-se sobre a justificativa poderosa da segurança e da proteção. Você não se incomoda mais em ser espionado, porque sabe que isso pode ser o seu salva-vidas em uma situação de perigo extremo. No Brasil, os roubos e a morte banalizada em um assalto aleatório. Na Europa e na América do Norte, o pavor dos ataques sincronizados que derrubam aviões, edifícios, explodem trens e ônibus.

A contrapartida da segurança é o controle da circulação, uma vez que a vigilância urbana se constitui da observação do comportamento a distância, resultando daí que a maioria das relações sociais já esteja envolvida em medidas antecipadas de precaução de riscos e perigos. Acatamos a invasão das nossas esferas individual e coletiva; aceitamos que possamos ser localizados, dirigidos e rastreados, porque isso parece ser, a cada ano, mais e mais parte de uma experiência urbana lastreada na regulação da vida cotidiana. A vigilância vem se tornando, de fato, serviço: tome-se, como exemplo, a gravação de cada clique em um website em benefício do mercado consumidor ou para as políticas de controle da pornografia on-line. Dados, neste caso, tornaram-se o verdadeiro material de vigilância, do mesmo modo que a vida privada se tornou prontamente traduzível em dados. ${ }^{21}$

21 A este respeito cf. a posição de Anthony Vidler, para quem "as questões que os arquitetos enfrentam dizem respeito não a como acomodar a revolução digital no espaço (o escritório doméstico está longe de ser um conceito 
Este é o ponto em que o efeito da tecnologia é tão-somente devastador, ponto em que a recepção na distração pensada por Benjamin encontra seu grande obstáculo. Quando pessoas se deixam ficar alheadas diante das telas, a tecnologia nada faz além de reproduzir a forma do culto. Nada há daquela percepção flexível e distanciada, então concebida por Benjamin como um modo analítico de perceber o mundo somente possibilitado pelos media tecnológicos. Ao contrário, o constante aumento da oferta tecnológica é diretamente proporcional ao isolamento de indivíduos do seu entorno físico; cada vez mais os moradores urbanos ficam retidos em cápsulas desenhadas para amortecer sua percepção do ambiente que os envolve.

Esta encapsularização da vida urbana leva Lieven de Cauter a diagnosticar uma "sociedade encapsulada"22 que denota, por um lado, uma cidade dominada tanto pela exclusão quanto pela simulação, em que o medo é o resultado; e, por outro, uma hipertrofia da esfera privada, em que casas são máquinas de conforto e anestesiamento.

Faz sentido falar de uma civilização capsular uma vez que certo limiar tenha sido cruzado. Precisamente por que o encapsulamento humano faz parte de uma lógica antropológica, que tem raízes profundas na cultura, um encapsulamento intenso (ou encapsulamento de segundo e terceiro graus), combinado com outros mecanismos, pode ser reafirmado. Neste caso, nos tornamos - mais do que nunca fomos e mais do que deveríamos ser — prisioneiros voluntários da arquitetura. ${ }^{23}$

A cápsula, que tanto pode ser uma ferramenta quanto uma extensão do corpo, funciona como um ambiente artificial controlado, um receptáculo que

revolucionário), mas, pelo contrário, de que modo o espaço (ou o seu correlato em objetos projetados para ele) configura uma branda resistência a esta vigilância virtual?" VIDLER, A., 1999, p. 81.

22 Adoto aqui a posição do filósofo Lieven de Cauter, belga que nasceu em 1959 e vive em Brussel. Com formação em história da arte e filosofia, escreveu sua tese de doutorado sobre Walter Benjamin, cujo título é Het Hiernamaals van de Kunst (1993). Suas publicações incluem: Archeologie van de Kick. Verhalen over Moderniteit en Ervaring (1995), De Dwerg in de Schaakautomaat - Benjamin's verborgen Leer (1999). Ele é co-autor de Dat is Architectuur! (2001). Leciona filosofia na escola de cinema Hij RITS, em Brussel e na Escola de Dança PARTS, também em Brussel; e pertence à Universidade Católica de Louvain, onde ensina na Escola de Arquitetura e integra, desde 1997, o grupo OSA, de pesquisa em arquitetura e urbanismo. Leciona também na Willem De Kooning Academie, em Rotterdam. Escreve regularmente nos periódicos Archis e Oase. Em 2004 reuniu vários de seus ensaios em uma tradução inglesa, intitulada The capsular civilization: On the city in the age of fear, Rotterdam: NAI publishers, 2004. Muitos dos seus escritos estão disponiveis no site http://www.oxumoron.org.

23 "This trend of evacuation of the public domain is called encapsulation (...) Very short: capsule architecture is the architecture of the new city." "We are all, in a sense, suburbanities, and even the convinced city dwellers have to fight the mechanism of the suburbanization of daily life... Our everyday life can be described as a movement, using transportation capsules, from one enclave or capsule, home, for instance, to another, campus, office, airport, all-in hotel, mall and so on. One might say that hyperindividualism plus the suburbanization of everydaylife is equivalent to capsularization." Cf. DE CAUTER The capsular civilization: On the city in the age of fear, p. 78. 
tem a finalidade explícita de isolar ou ignorar a paisagem externa, considerada sempre hostil. É interface que acaba por se tornar fim em si mesma, meio que se transforma literalmente em ambiente. ${ }^{24} \mathrm{Na}$ origem desses invólucros estão a velocidade e o transporte — trem, automóvel, avião e espaçonave são cápsulas reais (atualmente, carros hermeticamente fechados, com temperatura artificial e insulados para proteger os ocupantes dos choques e até da sensação de velocidade). Ao lado cápsulas reais, a tecnologia de micro eletrônica produziu cápsulas virtuais (iPod, telefone móvel, telas que nos retiram mentalmente do lugar em que nos situamos), confirmando um encapsulamento que já se fazia anunciar em 1969, no texto seminal de Kisho Kurokawa, Capsule declaration. Para o arquiteto integrante do movimento denominado metabolismo japonês, "a cápsula é arquitetura ciborgue. Homem, máquina e espaço constroem um novo corpo orgânico que (...) cria um ambiente por si só (...) um aparato que se transforma num espaço vivo, de tal modo que o homem não espera viver em outro lugar, é uma cápsula." 25

Na opinião de Lieven de Cauter, o emprego destas máquinas de estimulação determina uma lógica social fundada no hiperindividualismo amparado por tecnologias do isolamento, uma vez que o princípio de estimulação produzido nas cápsulas é uma poderosa membrana de representação (e reprodução do real, ainda que débil e ilusória). Quanto à repercussão de tal lógica nos espaços urbanos, prevê o filósofo que cada intervenção no desenho das cidades inevitavelmente envolverá fechamento, restrição ou cerceamento em algum grau. "Quanto maior a mobilidade, mais capsular nosso comportamento. Somos nômades sedentários", diz de Cauter, e, a seu ver, os elementos primários ("arquétipos simultaneamente arcaicos e hipermodernos") da arquitetura urbana do século XXI serão a cerca, o muro, o portão, a enclave, a barreira, a fortaleza, a fronteira. ${ }^{26}$ A arquitetura desta nova cidade é a arquitetura das cápsulas, cujo

24 "The word capsule comes from the Latin word capsa meaning box, container and capsa in it turn comes from capere meaning grasping, holding, keeping, in 'captivity' if you want. A capsule in the general sense is a 'holder', it is a 'container'. A capsule in the more specific sense (taking the space capsule as paradigm) can be defined as a tool or extension of the body, turning into an artificial environment that shuts out the outer, hostile environment. It is a medium that has become an ambient. So, as a tribute to McLuhan the shorted definition of a capsule would be: a capsule is a medium that has litterally become a 'milieu', an environment." Cf. DE CAUTER. The capsular civilization: On the city in the age of fear.

25 KUROKAWA, K. Metabolism in architecture, 1977. Apud DE CAUTER, 2005, p. 45.

26 Neste aspecto, parecem-me ser de suma importância as correlações, que ainda estão por ser investigadas, entre arquitetura e o que Michel Foucault denomina biopolítica (quando a vida biológica dos indivíduos é objeto de interferência política direta), termo que Giorgio Agamben retoma. Cf. AGAMBEN. Não à tatuagem política: " Qual é o estatuto jurídico-político dos cidadãos nos Estados supostamente democráticos em que vivemos? (...) procura-se, há alguns anos, nos convencer a aceitar como sendo as dimensões humanas e normais de nossa existência certas práticas de controle que sempre foram vistas como excepcionais e, na realidade, inumanas. Assim, ninguém ignora que o controle exercido pelo Estado sobre os indivíduos por intermédio do uso de dispositivos eletrônicos, como cartões de crédito ou telefones celulares, já atingiu 
papel político é evidente graças a seu efeito colateral: são ferramentas politicamente relevantes e eficientes, porque induzem os indivíduos a um constante entorpecimento. Walter Benjamin não teria apostado em algo mais desolador.

\section{5.}

Mesmo concluindo que o resultado da tecnologia onipresente em nossas vidas urbanas não será outro senão um "paradigma no qual entretenimento e controle, abertura e isolamento virão sempre juntos", ${ }^{27}$ as prospecções de Lieven de Cauter acerca da vida urbana futura não são, contudo, de todo desesperançadas. Para contornar a aporia em que desemboca sua oposição ao encapsulamento, ele aponta para algo como uma capacidade de resistência dos habitantes, traduzida em táticas que redesenhariam as relações tanto individuais quanto coletivas com os lugares. ${ }^{28}$

A hipótese da capacidade de resistência de habitantes e suas comunidades parece-me plausível, quando se trata de pensar a vida em uma grande metrópole. Quando as pessoas se sentem pertencentes ao mundo em que vivem, um envolvimento com os espaços que habitam é um bom ponto de partida. Somente assim o habitante urbano exercita práticas criativas em um contexto urbano consolidado, podendo, afinal, tornar-se "um protagonista em uma ação progressiva de seleção e definição de necessidades" da arquitetura que usa.

Reafirmar a força das comunidades ${ }^{29}$ pode, de fato, constituir o ponto central de um novo tipo de participação em arquitetura, uma vez que se assume

limites antes inimagináveis. Mas não é possível ultrapassar certos limiares no controle e na manipulação dos corpos sem penetrar em uma nova era biopolítica, sem dar mais um passo em direção ao que Foucault chamava de animalização progressiva do homem, implantada pelas técnicas mais sofisticadas. (...) O que está em jogo aqui é nada menos que a nova relação biopolítica supostamente 'normal' entre os cidadãos e o estado. Essa relação não tem mais nada a ver com a participação livre e ativa na esfera pública, mas diz respeito ao registro e fichamento do elemento mais privado e incomunicável da subjetividade: falo da vida biológica dos corpos. Assim, aos dispositivos da mídia que controlam e manipulam a palavra pública, correspondem, portanto, os dispositivos tecnológicos que inscrevem e identificam a vida nua. Entre esses dois extremos, de uma palavra sem corpo e um corpo sem palavra, o espaço daquilo que antes chamávamos de política se torna cada vez mais exíguo."

27 Cf. DE CAUTER. The capsular civilization: On the city in the age of fear, p. 34.

28 "Of course one should not forget, that encapsulation is always local, and by its essence a minority phenomenon: the outside is always bigger than the inside. So when describing this one deep rooted tendency in our society, we cannot deny that many different things are going on outside this logic. Outside the archipelago there is a sea of various interactions within old and new forms of community. Let's hope that all sorts of networking will prove stronger than encapsulation. Perhaps the proliferation of networks will ultimately overcome the proliferation of capsules. Perhaps." Cf. DE CAUTER. The capsular civilization: On the city in the age of fear, p .87.

29 Para retomar os argumentos de Carl Schorske, no texto referido, sobre o valor do agrupamento de pessoas em comunidades, se a experiência individual forma a cidade material e se é o subjetivismo que define a experiência da metrópole, tal cultura subjetivista - dada pela cultura urbana - submete-se a um nova ordem histórica, portanto temporal: na metrópole, à experiência individual sempre se faz somar a multidão. 
todo espaço enquanto espaço social, inerente à existência, de modo que "pessoas fazem os lugares, lugares fazem as pessoas". ${ }^{30}$ No que toca ao projeto de arquitetura, a consideração dessa dialética sócio-espacial estabelece uma práxis bem delineada, pois intervir no espaço passa a significar compreender sua dinâmica, entre a prática e a representação, e não mais manobrar seus atributos, buscando parâmetros para o desenho. Mas como saber das pessoas que habitam ou habitarão os espaços projetados? Como saber qual usuário agirá criticamente em uma arquitetura urbana tão sujeita à ação das máquinas de estimulação que são as cápsulas? Anthony Vidler coloca, nos seguintes termos, essa questão: "que tipo de sujeito é construído através do uso das ferramentas digitais que hoje produz esse tipo de superfície envolvente?"31

Para encaminhar uma resposta, penso no fator de intensificação dos ritmos da vida cotidiana que é a presença das redes sem fío. Ao redimensionar a mobilidade dos habitantes e alterar a freqüentação de espaços coletivos, essas redes constituem uma esfera pública mediada pela tecnologia, espécie de pólis cujo feitio é dado por um notebook, uma placa airport e o hábito de carregar a vida e o trabalho em uma bolsa às costas.

Em algumas cidades ao redor do mundo forma-se uma aliança entre o consumo e os provedores de Internet sem fio, que tem promovido uma extensão dos espaços domésticos e/ou de trabalho e, por conseguinte, ensaiado uma forma de sociabilidade. Bibliotecas, campi universitários, cafés, livrarias, farmácias, lojas - todos são lugares que permitem o uso de rede, conexão e serviços de cópia, impressão, reprodução de documentos, como um serviço paralelo à sua principal função programática, o que resulta no hábito de consumir o que era originariamente oferecido ali. Estratégia é o outro nome deste pacto, em que já se fazem notar iniciativas vigorosas na direção de sua finalidade. Uma reportagem de jornal fotografou recentemente, à hora do almoço, os parques da cidade de Philadelphia, nos Estados Unidos, e relatou pelo menos um caso exemplar: um mestre de obras, 62, trabalhador free-lancer, que, em seu intervalo, desce para o parque para checar as mensagens eletrônicas contendo prováveis ofertas de próximos trabalhos. ${ }^{32}$ A administração daquela cidade inclui na oferta de serviços públicos, desde o ano de 2004, o provimento de Internet a baixo custo para uma área de $350 \mathrm{~km}^{2}$ dentro do perímetro urbano. ${ }^{33}$

30 LEFEBVRE. La Production de l'Espace, p. 46.

31 VIDLER. Screened Identities. In: TSCHUMI. (Ed.). The state of architecture at the beginning of the 21st. Century, p. 108-109.

32 "whenever I am in the centre city, this is where I come to get my e-mail. Otherwise, I am running around looking for a Starbucks or something. It takes too much time." In: MCCARTHY. US city cuts strings from corporations'Net.

33 MCCARTHY. US city cuts strings from corporations'Net. 
As companhias de tv a cabo e telefonia contestaram judicialmente a concorrência do governo e, como perderam a disputa naquela cidade, já se armaram juridicamente para impedir que outras municipalidades tomem igual iniciativa, juntando à oferta de infra-estrutura básica (luz, água e telefone) o acesso digital em alta velocidade. ${ }^{34} \mathrm{O}$ objetivo a curto prazo é incluir uma grande parcela da população de média e baixa rendas na "era digital", mas a cidade americana, na verdade, replica uma estratégia de planejamento já bastante presente na Ásia, onde boa parte das cidades assumiu a ferramenta da Internet de alta velocidade como elemento crucial nas políticas de desenvolvimento urbano. ${ }^{35}$

A experiência e a conceitualização da cidade realizada por usuários vivendo sob tais políticas urbanas parecem se alterar a ponto de definir elementos para uma nova dinâmica da forma urbana, mesmo que em minúsculas transformações. ${ }^{36}$ Ainda que vinculada ao consumo, portanto implicada em funcionalização e instrumentalização dos usos, não há dúvidas de que esta flexibilização é, em parte, positiva — quando se trata de estabelecer traços de convivência.

Além disso, a alteração das relações espaciais entre os espectadores e o que eles vêem reflete mudanças paralelas na tecnologia e no modo como ela é usada. Ainda que no interior de lojas de bebida e comida — mas principalmente porque começam a fazer parte dos serviços incluídos em preços de aluguel de moradias temporárias - as redes sem fio têm permitido que os trabalhadores estendam suas áreas de trabalho para fora dos escritórios, que os alunos das universidades ocupem espaços abertos espalhados pelos campi, fundindo a pausa e o trânsito nos lugares públicos.

São estes territórios multidimensionais - cafés, parques, campi, terraços de bares, mesas nas calçadas, lavanderias no subsolo - que podem propiciar novos agrupamentos; as mais diversas comunidades podem nascer nestes

34 Na Pensilvânia uma grande companhia provedora aprovou um projeto de lei que obriga os governos a discutir primeiramente com as companhias antes de prosseguirem com tais políticas, sob o argumento de que é baixíssimo o preço que a prefeitura de Philadelphia pretende cobrar, o que poria rapidamente fim aos lucros vultosos das companhias provedoras, uma vez que estas cobram em torno de quarenta dólares mensais, e a prefeitura conseguiu baixar o preço do mesmo período para dez e vinte dólares.

35 "Esta é uma parte da infra-estrutura do século XXI. As cidades estão em competição e a cidade que oferecer os mais atrativos serviços atrairá tanto mais residentes como mais e maiores investimentos." MCCARTHY. US city cuts strings from corporations'Net.

36 Gosto muito de utilizar um exemplo dado por Jaime Lerner para pensar no quanto a informalidade dos usos pode contribuir para a transformação da vida cotidiana das metrópoles, a ponto de caracterizar e consolidar os arranjos de determinada arquitetura urbana, neste caso, os fluxos e ritmos noturnos na cidade de Nova York. Diz Lerner: "Costumo dizer que Nova York deveria erguer um monumento ao coreano desconhecido. Os integrantes deste povo prestam um serviço extraordinário à cidade com suas grocery stores, suas deli stores abertas $24 \mathrm{~h}$ em qualquer canto da cidade." Cf. LERNER. Acupuntura urbana. 
lugares de performance onde a tecnologia é experimentada de modo corpóreo - de tal maneira que a cidade confirma-se como conjunto de espaços de tradução, isto é, situações urbanas que permitem estabelecer conexões entre estas trocas on-line (a navegação na Internet) e a tradicional realidade urbana, biológica e social dos corpos humanos situados em lugares.

$\mathrm{O}$ mestre de obras de Philadelphia remete à amplitude do tema dos lugares abertos à intervenção de seus habitantes. A sua atitude, em que o uso renova o lugar ao adaptá-lo às demandas, explicita a necessidade de que a arquitetura pense o potencial dos usos temporários como motor de mudança urbana, pois reúne a experimentação do espaço arquitetônico (visível) ao uso das redes (invisível). Cada vez mais os habitantes têm habilidades diversas enquanto receptores de informação - são moventes, são imersivos, ou contemplativos — e, com as mídias eletrônicas (associadas a informação de massa, política, vida familiar, trabalho e entretenimento), tendem a interrogar, subverter e transformar outros contextos de linguagens, reverberando no modo como gerem seus espaços próprios..$^{37}$ É uma transformação na estrutura humana de percepção nada desprezível para quem desenha lugares.

Compreender os usuários da cidade atual requererá tanto informação como crítica. Na verdade, é uma operação política, pois implica aceitar o conflito, a confrontação, uma vez que as únicas regras nesta investigação são a contingência e a imprevisibilidade que dela decorre. Arquitetos, em geral, não estão dispostos a pagar o ônus de uma real compreensão política dos fatos em termos de compromisso e crítica profundos. Mas qualquer teoria da participação em arquitetura deve atrelar-se necessariamente à consciência política, o que é o contrário do desengajamento. Em um processo participativo os indivíduos são capazes de interrogar a heterogeneidade de uma situação, reconhecer sua própria posição e então ir além dela, abrindo-a para novos significados, novas possibilidades. A participação, afinal, serve como parte de um processo educativo, no qual a imaginação é ferramenta coletiva para a transformação do real, para o estabelecimento do horizonte de possibilidades.

37 “(...) por trás da aparente imobilidade corporal do usuário plugado no ciberespaço, há uma exuberância de instantâneas reações perceptivas em sincronia com operações mentais. Estão em atividade mecanismos cognitivos dinâmicos, absorventes, extremamente velozes, frutos da conexão indissolúvel, inconsútil, do corpo sensório-perceptivo à mente, sem os quais o processo perceptivo-cognitivo inteiramente novo da navegação não seria possível." SANTAELLA. Corpo e comunicação. Sintoma de Cultura. 


\section{6.}

É verdade que não somos os Jetsons, mas já estamos quase em Gattaca, a cidade dos scanners de retina. Se ficamos com Lefebvre, afirmando que o espaço é parte do processo de organização e transformação social, é possível que possamos relacionar as representações coletivas da arquitetura contemporânea à cidade e às novas mídias. Aos arquitetos, cabe insistir em encontrar e sustentar caminhos para uma produção arquitetônica que seja politicamente consciente e transformadora. É daí, e só aí, que decorre nosso reconhecimento de uma nova condição urbana, como habitantes de uma espacialidade que tem na mobilidade das redes um forte catalisador da criatividade difusa e da produção imaginária. Entretanto, isso só será efetivo se necessariamente implica pensar formas cotidianas de se pronunciar e de atuar nesses espaços.

A passividade dos que habitam, mas que poderiam e deveriam "habitar como poetas" (Hölderlin), não poderia ser comparada ao estranho bloqueio que freia o pensamento arquitetural e urbanístico? Os projetos são atingidos por uma espécie de maldição. Eles não podem ir além da utilização de alguns procedimentos gráficos ou tecnológicos. A imaginação não consegue alçar vôo. (...) não existe pensamento sem referência a uma prática (aqui, a do habitar e do uso; mas que prática é possível se o habitante e o usuário permanecem mudos?). ${ }^{38}$

\section{Referências}

AGAMBEN, G. Não à Tatuagem Política. Folha de S.Paulo, São Paulo, 2004. Caderno A, p. 18.

BENJAMIN, W. The work of Art in the age of its technological reproducibility, $2^{\text {nd }}$ Version. In: . Selected Writings. Edited by Michael Jennings, Howard Eiland and Gary Smith. Cambridge, MA: The Belknap Press of Harvard University Press, 2002.

BLUNDELl-JONES, P.; TILL, J.; PETRESCU, D. (Ed.). Architecture and participation. New York: Spon Press, 2005.

BRIDGE, G. A companion to the city. London: Routledge, 2004.

.The Blackwell city reader. Oxford: Blackwell Publishing Ltd., 2002. (Blackwell readers in Geography)

CUPERS, K. Spaces of uncertainty. Wuppertal: Müller und Busmann, 2002.

38 LEFEBVRE. A revolução urbana, p. 165. (grifo no original) (desculpe-me a interferência, é que tenho o livro e me interessei pela citação.) 
DE CAUTER, L. The capsular civilization: on the city in the age of fear. Rotterdam: NAI Publishers, 2004.

. The capsule and the network. Notes toward a general theory. OASE Architectural Journal Re: Generic City. Winter 2001.

DEWSBURY, J. D. Performativity and the event. Disponível em: <http:// www.virtualsociety.sbs.ox.ac.uk/matcon/abstd.htm>. Acesso em: 20 maio 2005.

DILLER, E. Blur. The making of nothing. New York: Harry N. Abrahams; Inc. Publishers, 2002.

GRAHAM, S. Excavating the material geographies of cybercities. In: GRAHAM, S. (Ed.). Cybercities reader. London: Routledge, 2004.

. From dreams of transcendence to the remediation of urban life. In: GRAHAM,

S. (Ed.). Cybercities reader. London: Routledge. 2004. p. 1-30. (Urban series readers). GRAHAM, S. (Ed.). Cybercities reader. London: Routledge, 2004.

GUMBRECHT, H.-U. Mapping Benjamin. The work of art in the digital age. Stanford, CA: Stanford University Press, 2003.

HALL, P. Cities of tomorrow. An intellectual history of urban planning and design in the 20th. C. London: Blackwell, 2002.

HILLIS, K. Digital sensations - Space, identity, and embodiment in virtual reality. Minneapolis: University of Minnesota, 1999.

HUGHES, J. Non plan. Essays on freedom participation and change in modern architecture and urbanism. London: Architectural Press, 2000.

MCCARTHY, S. US city cuts strings from corporations' Net. The Globe and the Mail, Toronto, Saturday, 7 May 2005, p A14.

LEFEBVRE, H. A revolução urbana. Belo Horizonte: Editora UFMG, 1999. . La Production de l'Espace, 46.

LERNER, J. Acupuntura urbana. Rio de Janeiro: Record, 2003.

LOWE, D. M. History of bourgeois perception. Chicago: University of Chicago Press, 1982. NEUERER, G. Untitled (experience of place). London: Koenig books, 2002.

OASE Architectural Journal. The Visible and the Invisible, OASE Architectural Journal, summer 2002.

PATTEEUW, V. The conspiracy against the city, Lieven de Cauter in Conversation with Richard Plunz. In: PATTEEUW, V. Eine Stadt in Bewegung/ Une Ville en Mouvement/ A Moving City. Brussels, Studio Open City, 1998.

PETRESCU, D. Losing control, keeping desire. In: BLUNDELL-JONES, P.; TILL, J.; PETRESCU, D. Architecture and participation. New York: Spon Press, 2005.

SALTER, C. From representation to performance. Responsive Public Space. Disponível em: <http://www. sponge.org>. Acesso em: 14 maio 2005.

. Responsive audio/visual spaces: immersion, performance and the elasticity of time. Elektra 6IX Arts Numériques + Digital Arts. Usine C, Montreal: elektrafestival.ca. p. 13, Friday, May 13, 2005. (Catálogo do festival).

SANTAELLA, L. Corpo e comunicação. Sintoma de Cultura. São Paulo: Paulus Editora, 2004. 
Culturas e artes do pós-humano: da cultura das mídias à cibercultura. São Paulo: Paulus Editora, 2003.

SCHORSKE, C. A idéia de cidade no pensamento europeu: de Voltaire a Spengler. In: SCHORSKE, C. Pensando com a História. Indagações na passagem para o Modernismo. São Paulo: Companhia das Letras, 2000. (Publicado originalmente em The Historian and the City. Cambridge, MA: MIT Press, 1963).

SIMMEL, G. The Metropolis and the mental life. In: FEATHERSTONE, M.; FRISBY, D. Simmel on Culture. London: Routledge, 1999. p.174-190.

THRIFT, N. Inhuman Geographies. Landscapes of speed, light and power. In: GRAHAM, S. (Ed.). Cybercities reader. London: Routledge, 2004. p. 30-93. (Urban Series Readers).

TILL, J. Lost Judgment: EAAE Prize 2003-2005. Londres: EAAE Prize, 2005.

. The negotiation of hope. In: BLUNDELL-JONES, P.; TILL, J.; PETRESCU, D. (Ed.). Architecture and participation. New York: Spon Press, 2005.

TOWSEND, A. Life in the real time city: mobile telephones and urban metabolism. Journal of Urban Technology, v. 7, p. 85-109, 2000.

VESELY, D. Architecture in the age of divided representation. The question of creativity in the shadow of production. Cambridge, MA: MIT Press, 2004.

. The Nature of communicative space. In: . Architecture in the age of divided representation. The question of creativity in the shadow of production. Cambridge, MA: MIT Press, 2004.

VIDLER, A. Bodies in space/Subjects in the city. In: BRIDGE, G. (Ed.). The Blackwell city reader. Oxford: Blackwell, 2002. p. 46-52.

Photourbanism: planning the city from above and from below. In: BRIDGE, G. (Ed.). A companion to the city. London: Blackwell, 2000. p. 35-45.

. Robots in house: surveillance and the domestic Land-Scape. Daidalos, v. Architecture goes Landscape, n. 73, p. 78-87, out. 1999.

Screened Identities. In: TSCHUMI, B. (Ed.). The state of architecture at the

beginning of the 21st. Century. New York: The Monacelli Press; Columbia books of architecture, 2003. p. 108-109.

ZACK, J. Eilfried Huth. Architekt. Varietät als Prinzip. Berlin: Gebr. Mann Verlag, 1996. 